\title{
Nymphal biology of Brachyptera risi (Morton, 1896) (Plecoptera: Taeniopterygidae) in a North Apennine stream (Italy)
}

\author{
Stefano Fenoglio, Tiziano Bo, M. Jesus López-Rodríguez \\ \& José Manuel Tierno de Figueroa
}

Fenoglio, S., Bo, T., López-Rodríguez, M. J. \& Tierno de Figueroa, J. M. 2008: Nymphal biology of Brachyptera risi (Morton, 1896) (Plecoptera: Taeniopterygidae) in a North Apennine stream (Italy). — Entomol. Fennica 19: 228-231.

Some aspects of the life history of a population of Brachyptera risi were investigated in a North Apennine stream and compared with previously studied European populations. In our study area, this species showed a univoltine fast seasonal life cycle. Nymphs were present from January to the beginning of May, probably spending the rest of the year mainly in egg diapause. Fine particulate organic matter was the principal component of the diet, while diatoms and other algae were also found in the guts. This finding suggests the existence of greater trophic plasticity of the species. Individuals of this population act as gatherer-collectors but not as scrapers as usually pointed out for other European populations. We also detected considerable amounts of animal matter in the gut contents. The density of $B$. risi nymphs in the study area was very variable during the study period, ranging from 0 to $2,348 \mathrm{ind} / \mathrm{m}^{2}$.

S. Fenoglio \& T. Bo, Dipartimento di Scienze dell'Ambiente e della Vita, Università del Piemonte Orientale, Via Bellini 25, 15100, Alessandria, Italy; Emails:fenoglio@unipmn.it (correspondingauthor),tbo@unipmn.it

M. J. López-Rodríguez \& J. M. Tierno de Figueroa, Departamento de Biología Animal, Facultad de Ciencias, Universidad de Granada, 18071, Granada, Spain;E-mails:manujlr@ugrs.es,jmtdef@ugr.es

Received 31 August 2007, accepted 12 November 2007

\section{Introduction}

Brachyptera risi (Morton, 1896) is a species widely distributed in Europe. In Italy, it is a common rheophilous inhabitant of the basal and submontane streams of the Alps and Apennines (Ravizza \& Fochetti 1999). Several aspects of adult and nymphal biology, such as nymphal feeding, egg development, population movements or adult dispersal, have been studied in different parts of the continent, particularly by Madsen (1976) and Madsen \& Butz (1976), but also by Brinck (1949) and Khoo (1964).

This relatively wide knowledge of the species biology is quite unusual in stonefly literature. For this reason, studies performed in new areas could be interesting in order to compare findings and to obtain a general point of view of the nymphal biology. Up to now, usually only punctual studies on particular stonefly species from certain areas are available, making it impossible to detect if their characteristics are generalities of the species or concrete population adaptations to particular habitats. 


\section{Study area, material and methods}

We conducted quantitative Surber sampling in the Caramagna stream (Cassinelle, Italy: UTM 464261-4939532; $280 \mathrm{~m}$ a.s.1.) from 4 January 2005 to 2 March 2006. Samplings were made mainly every two weeks. In the sampling station, the stream is characterized by a width of 2.0-2.5 $\mathrm{m}$, a moderate current velocity, a riverbed composed of $10 \%$ sands, $30 \%$ gravels, $50 \%$ pebbles and $10 \%$ rocks, and the existence of riffles alternating with pools. Samples were collected randomly in order to represent every possible mesohabitat, using a Surber sampler.

Measures of total length, pronotal width, and third leg femur length were taken using a Nikon stereomicroscope at 60-100× magnifications, with an accuracy of $0.1 \mathrm{~mm}$.

For the study of the species diet, Bello \& Cabrera's transparency method was used (Bello \& Cabrera 1999), as in other papers studying Plecoptera nymphal feeding (Tierno de Figueroa et al. 2003, Bo \& Fenoglio 2005, López-Rodríguez $\&$ Tierno de Figueroa 2006). We identified the different components of the gut contents and each animal item was sorted out to the family level when possible and counted. For the remaining parts of gut content, we quantified the percentages that they occupied in the guts. Statistical analyses were performed with Statistica 7.1 (StatSoft 2005).

\section{Results and Discussion}

\subsection{Life cycle}

In total, we took 109 Surber samples and we collected and measured $401 \mathrm{~B}$. risi nymphs. The three measured parameters (total length, pronotum width, and third leg femur length) were highly correlated (Gamma correlation $=0.81$ for pronotum width $v s$. femur length; Gamma correlation $=0.82$ for pronotum width $v s$. total length; correlation $=0.77$ for total length $v s$. femur length; $p<0.05$ for all cases). Thus, we employed total length as size indicator for representing the nymphal growth.

As shown in Fig. 1, nymphs were present in benthos for a period of four months, from January

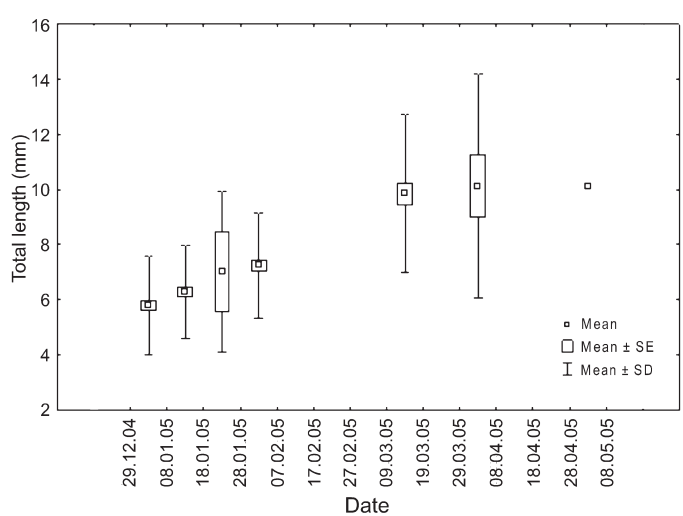

Fig. 1. Appearance and growth of $B$. risi in the Caramagna stream.

to the beginning of May. Nevertheless hatching period can begin slightly before, probably depending on the particular environmental conditions (Fig. 2). In fact, studies in other areas show that the period of nymphal growth can expand even from the end of October to the beginning of May (Brinck 1949, Hynes 1961).

We suppose that hatching occurs at the end of autumn or beginning of winter: $B$. risi spends the rest of the year in egg stage, probably experiencing an egg diapause, or as nymphs of first instars living in the interstitial zone. These data support that of other studies, suggesting the existence of a long incubation period for this species, including an egg diapause, and a posterior fast nymphal growth (Khoo 1964). In relation to this, Hynes (1970) noticed that this species was not sensitive to cold weather, and in fact young nymphs do not

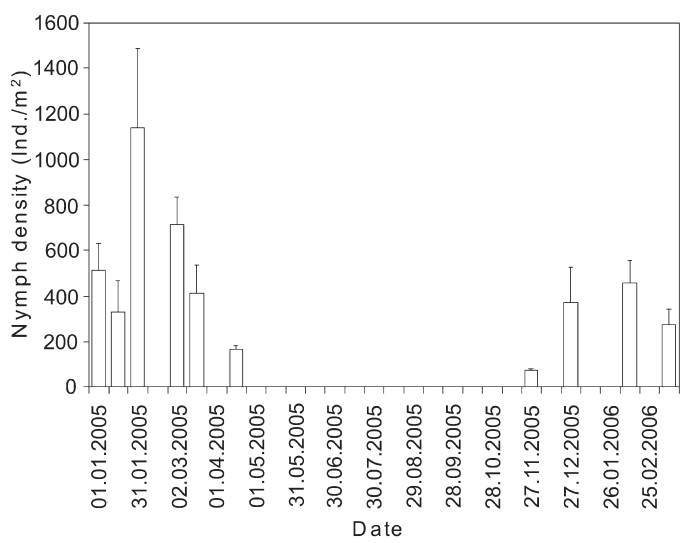

Fig. 2. Density of $B$. risi nymphs (mean $\pm \mathrm{SE}$ ). 
Table 1. Gut contents (\% occupied in the gut) of $B$. risi nymphs in the studied area.

\begin{tabular}{lrrlrr}
\hline & N & Mean & Std. Dev. & \multicolumn{2}{c}{ Min. Max. } \\
\hline \% Absolute & 243 & 28.29 & 29.98 & 0 & 100 \\
\% FPOM & 174 & 45.46 & 28.5 & 0 & 100 \\
\% Algae indet. & 174 & 6.45 & 13.59 & 0 & 66 \\
\% Diatoms & 174 & 0.76 & 4.96 & 0 & 33 \\
\% Sand & 174 & 34.22 & 30.06 & 0 & 100 \\
Trichoptera & 174 & 0.01 & 0.08 & 0 & 1 \\
Chironomidae & 174 & 0.02 & 0.17 & 0 & 2 \\
Simuliidae & 174 & 0.01 & 0.08 & 0 & 1 \\
\hline
\end{tabular}

a) $\%$ of gut occupied by food.

b) $\%$ of gut occupied by fine particulate organic matter.

appear until the water is cold at the end of autumn (Hynes 1961).

Based on the data, the life cycle of this species is univoltine, and could be classified as "fast seasonal" following Hynes (1970). The nymphal growth was relatively constant through the winter and the beginning of spring, when emergence occurs. Ravizza \& Fochetti (1999) pointed out a long flight period for this species in Italy, from February to June, coinciding with the period reported by other authors in other countries (Brinck 1949). Nevertheless, the local emergence depends on the altitude and latitude, and consequently on the temperature (Brinck 1949, Ravizza \& Fochetti 1999), the flight period being shorter in particular localities.

\subsection{Feeding habits}

Totally of 243 gut contents were analysed (Table 1) and 174 of them presented some kind of matter in the gut. Fine particulate organic matter (FPOM), the main component of the diet, was found in the $63.4 \%$ of the individuals. Diatoms and other algae were present in a lower number of individuals (1.6\% and $13.6 \%$ respectively). Curiously, there was a high percentage of individuals $(49.8 \%)$ with sand in their gut. We also detected that some nymphs showed animal matter inside the gut, indicating the possibility of predator or necrophagous behaviour or, alternatively, of accidental ingestion. All these data suggest that the studied $B$. risi nymphs act as gatherer-collectors (sensu Cummins \& Merritt 1996), ingesting occasionally some animal matter.

Comparing with data from literature, some notable differences are found. Many authors (for instance Hynes 1941, 1976, Brinck 1949, Lillehammer 1988) pointed out that $B$. risi feed mainly on periphyton, indicating that this species acts as a scraper (sensu Cummins \& Merritt 1996). However, in contrast to the findings of these authors, nymphs of the Caramagna population consume almost no diatoms and other algae. Thus, the high percentage of detritus found in their guts would be collected from the substrate and not from the biofilm. Although the presence of animal remains in the gut of this species was previously recorded by Brinck (1949), this is not usual for members of the superfamily Nemouroidea.

\subsection{Population dynamics}

The density of $B$. risi nymphs was very variable in the study area (Fig. 2). Considering only the period in which nymphs were present in benthos, density ranged from 16 to $2,348 \mathrm{ind} / \mathrm{m}^{2}$ (mean $466.8 \mathrm{ind} / \mathrm{m}^{2}$ ). This high spatial and temporal variability could be due to i) the preference of the species for certain substrates [for instance Madsen (1976) pointed out the preferred substrate is the current-exposed surfaces of smooth stones] conditioning a contagious distribution, and ii) the displacement of nymphs during the season [as observed by Madsen (1976) in East Judtland].

Regarding the first cause, our sampling station presented a relatively diverse substrate that could explain at least a part of the spatial variation in nymphal density. Regarding the temporal variation, the highest density values occur at the beginning of winter, when all the eggs have hatched, and a relative high density is maintained through the winter [as pointed by Hynes (1961) for this species in a Welsh stream]. The decrease observed later could probably be due to the strong increase of temperature (typical of Apenninic streams of Piemonte) and, at the end of the nymphal growth, to the adult emergence. 


\section{References}

Bello, C. L. \& Cabrera, M. I. 1999: Uso de la técnica microhistológica de Cavender y Hansen en la identificación de insectos acuáticos. - Bol. Entomol. Venez. 14: 77-79.

Bo, T. \& Fenoglio, S. 2005: Age-related shift in the diet of Perla marginata in a woodland Apenninic creek of NW Italy (Plecoptera, Perlidae). — Entomol. Gen. 28: 147-154.

Brinck, P. 1949: Studies on Swedish Stoneflies (Plecoptera). - Opusc. Entomol. 11: 1-250.

Cummins, K.W. \& Merritt, R.W. 1996: Ecology and distribution of aquatic insects. - In: Merritt, R. W. \& K. W. Cummins (eds.), An introduction to the aquatic insects of North America: 74-86. Kendall \& Hunt Publ., Dubuque, Iowa. 862 pp.

Hynes, H. B. N. 1941: The taxonomy and ecology of the nymphs of British Plecoptera with notes on the adults and eggs. — Trans. R. Entomol. Soc. Lond. 91: 459557.

Hynes, H. B. N. 1961: The invertebrate fauna of a Welsh mountain stream. - Arch. Hydrobiol. 57: 344-388.

Hynes, H. B. N. 1970: The ecology of running water. The Blackburn Press, Caldwell, New Jersey. 555 pp.

Hynes, H. B. N. 1976: Biology of Plecoptera. - Ann. Rev. Entomol. 21: 135-153.
Khoo, S. G. 1964: Studies on the biology of Stoneflies. $\mathrm{Ph}$.D. thesis, University of Liverpool, Liverpool. 162 pp.

Lillehammer, A. 1988: Stoneflies (Plecoptera) of Fennoscandia and Denmark. Scandinavian Science Press Ltd., Leiden. 165 pp.

López-Rodríguez, M. J. \& Tierno de Figueroa, J. M. 2006 : Life cycle and nymphal feeding of Rhabdiopteryx christinae Theischinger, 1975 (Plecoptera, Taeniopterygidae). - Ann. Soc. Entomol. Fr. 42: 57-61.

Madsen, B. L. 1976: Population dynamics of Brachyptera risi nymphs (Plecoptera). — Oikos 27: 281-287.

Madsen, B. L. \& Butz, I. 1976: Population movements of adult Brachyptera risi (Plecoptera). — Oikos 27: 273280.

Ravizza, C. \& Fochetti, R. 1999: I Plecotteri Taeniopterygidae della regione italica (Plecoptera). - Mem. Soc. Entomol. Ital. 77: 123-159.

StatSoft Inc. 2005: STATISTICA (data analysis software system), version 7.1. [www document] URL http// www.statsoft.com.

Tierno de Figueroa, J. M., Sezzi, E. \& Fochetti, R. 2003: Feeding in the genus Tyrrhenoleuctra (Plecoptera Leuctridae). — Boll. Soc. Entomol. Ital. 134: 207 210. 